\title{
BLASTing the zombies! \\ Creative ideas to fight finals fatigue
}

W e see them at the end of every semesterstudents with vacant expressions who murmur unintelligible things to themselves as they shuffle from the library to their classrooms for exams. They forego sleep, food, and even basic hygiene in a last-ditch effort to do well on their finals. When asked on Facebook how students at the University of North CarolinaCharlotte planned to use J. Murrey Atkins Library during exams, many admitted that it would become a new home for them. The imminent zombie invasion became frighteningly apparent when one student commented, "I will be drinking a lot of Red Bull and starting a new movement \#OccupyAtkinsSpring2012Finals." Clearly, this semester was going to end with someone's brains being eaten unless we took decisive action. We decided to BLAST the zombies.

\section{Planning}

Finals are a key time to support—and engage —stressed students. Like other academic libraries, Atkins Library has provided free coffee, candy, coloring books, and such during this time. However, we decided to greatly expand our efforts for Spring 2012 finals. We started by establishing a committee of people with creative ideas who were willing to work hard for the 11 days of exams. We quickly netted nine faculty and staff from various departments who began meeting one month prior to the start of finals. After exploring numerous ideas, we agreed on offering BLAST (Bounce, Lounge, Art, Sleep, and Touch) as the foundation for our activities. ${ }^{1}$ Although Atkins Library's brand claims "A New Way to Think," this specific event offers students a space not to think through creative relaxation.

An online volunteer management site, SignUpGenius.com, was used to manage the volunteer sign-up and responsibilities needed for four-hour shifts during the 11-day period. This greatly reduced administrative time spent creating and distributing instructions, sending reminders, and making schedule changes.

We also partnered with a local organization, the Library Dog Therapy Group, organized by Professor Emeritus and Past Atkins Library Interim University Librarian Carole Runnion. We found this group to be a great addition to our offerings. Students were thrilled with the opportunity to love on a furry friend-especially those who missed their family dogs while away at college.

First, the committee wanted a room that was close to an entrance. It also needed to be large enough for all the activities we planned, yet contain the noise that was bound to be generated. Fortunately, the library had recently opened a new entrance on the ground floor, and we were able to claim a large space that had not been upfitted for group study rooms.

Next, the committee organized offerings and activities that surrounded the BLAST theme:

(B)ounce: Various games involving balls were supplied to help students blow off some steam. Most popular were a Ping-Pong game,

\footnotetext{
Jean Hiebert is health and human services librarian, e-mail: jhiebert@uncc.edu, and Shelly Theriault is marketing and communications manager at University of North Carolina-Charlotte, e-mail: stheriau@uncc.edu (c) 2012 Jean Hiebert and Shelly Theriault
} 
lots of colorful plastic balls, and a small basketball goal.

(L)ounge: Comfortable seating groups and low tables softened the atmosphere and provided a place for students to actually relax or even catch a few desperate winks.

(A)rt: Easy creativity is a great way for students to disengage from such a strong emotional level and calm their minds. No artistic skills needed, talent is in the eye of the beholder. Play Dough, coloring books, puppet crafts, and puzzles were plentiful and greatly appreciated.

bers took a trip together to purchase all items up-front.

\section{Implementation}

We set up the back of the room with PingPong, miniature basketball, and paddle balls. The "art corner" had several tables with crayons, coloring books, Play Dough, and paper bag puppet supplies. A large whiteboard was also placed with a daily lead-in question that students could answer, such as, "How many hours have you slept within the last 24 hours?"

Our building operator provided plenty of comfortable seating and small tables, which we loaded up with magazines and games like Jenga and Boggle. Another large table offered the disposable pillows which were, unsurprisingly, more popular at night. In response, a student posted to our Facebook page: "We have disposable pillows? Is this real life?"

Atkins Library is open $24 / 7$ during exams, so SignUpGenius. com was used to schedule restocking and tidying the room every four hours. All library employees were encouraged to

(S)leep: Boxes containing disposable pillows were placed (and replaced) in the break room.

T(ouch): Several therapy dogs arrived with their owners three different times during finals to mingle, relax, and wet nose some very happy students.

Coffee, hot water (for the hot chocolate and tea), cups, stirrers, and sleeves were ordered and supplied continuously from Peet's, the library's café. A microwave from the staff break room was temporarily relocated to the area. Large trash cans were placed by the door and Housekeeping was very helpful in keeping them emptied for us. Disposable pillows were ordered from an online vendor. We asked local dentists to donate toothbrushes and toothpaste.

An extensive supply list was created, including hot chocolate packets, green tea, and art supplies being the bulk of items. Two mem- volunteer.

The students used 1,400 coffee cups, 2 cases of creamer, 2 gallons of milk, 7 boxes of stirring sticks, 2 cases of sugar, and one case each of raw sugar, Equal, and Splenda. The students also consumed 42 boxes of cocoa and 19 boxes of green tea. The cocoa was very popular, and one student tweeted, "Mmmm hot chocolate w/ marshmallows, compliments of atkins library \# uncc." We also placed a microwave nearby for students who brought their own food or who heated water if the dispenser of hot water ran out before we could replace it. We surprised the students on Reading Day with free pizza at 11 p.m. Forty pizzas were gone in 17 minutes.

Postcards saying "Don't worry, I'm studying in the library," were also offered for students to send to family and friends. For a generation that grew up with computers, postcards are a bit of 
a novelty, so we taped a sample to the table so that they would know how to address them. They were gathered at the beginning of each shift, and the director of library development mailed 450 of them.

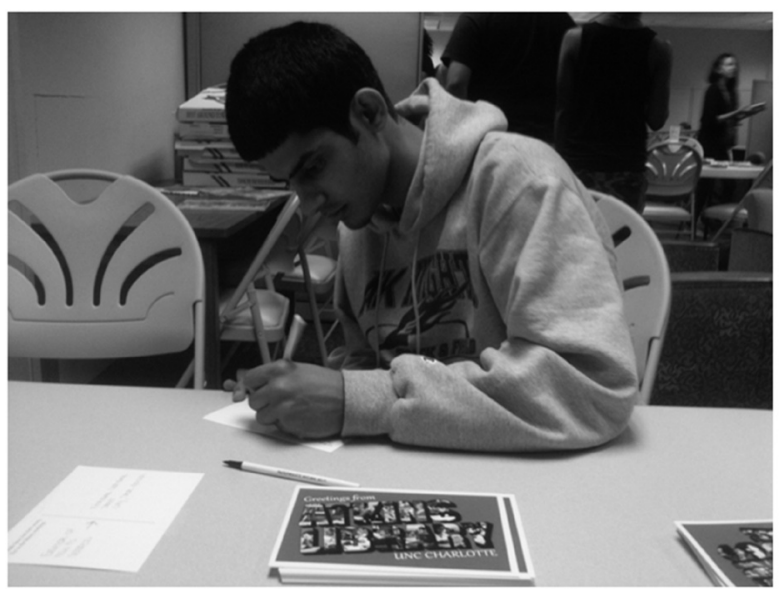

and university), building signage, and word of mouth served as excellent marketing tools.

Using the pet therapy sessions as a key angle, we secured an article displayed in the university's homepage highlights, beginning a few days prior to finals and throughout.

We also advertised the pet therapy visits with signs of the individual dogs accompanied by meaningful and cute sayings, telling students when the dogs would be here. Each sign had tear-away portions at the bottom with the dates and times so that the students would have reminders. The university's broadcasting division sent a videographer who created a touching video of the dogs' first visit and the student reaction to them. It was posted on the university's YouTube site ${ }^{2}$ and e-mailed to

Four hundred and fifty postcards were mailed to students' fam- various units and departments. Fiily and friends.

\section{Funding and marketing}

Budgets are tight and fiscal responsibility is certainly an important factor for marketing and student engagement activities. With the increasing popularity of the finals break room from past semesters, it was decided to move a significant amount of our marketing dollars from another event, Week of Welcome (WOW), to this.

WOW is an annual universitywide event where incoming freshmen and transfer students are introduced to the campus' resources and organizations during the first five days of classes. Atkins Library historically participates in a significant way during this time, engaging upwards of 1,000 students during a three-hour event timeslot. Exams, however, provided us with a larger captive audience, lasting 11 days versus a few seconds. As one student tweeted, "holy atkins library right now! \#packed." Facebook posts, tweets (by the library nally, The Charlotte Observer - the

largest newspaper in the Piedmont area — sent a reporter, and her article, "Students Can Go to The Dogs at Exam Time" appeared in a Sunday edition.

In addition, one committee member dressed in scrubs and handed out "prescriptions" for

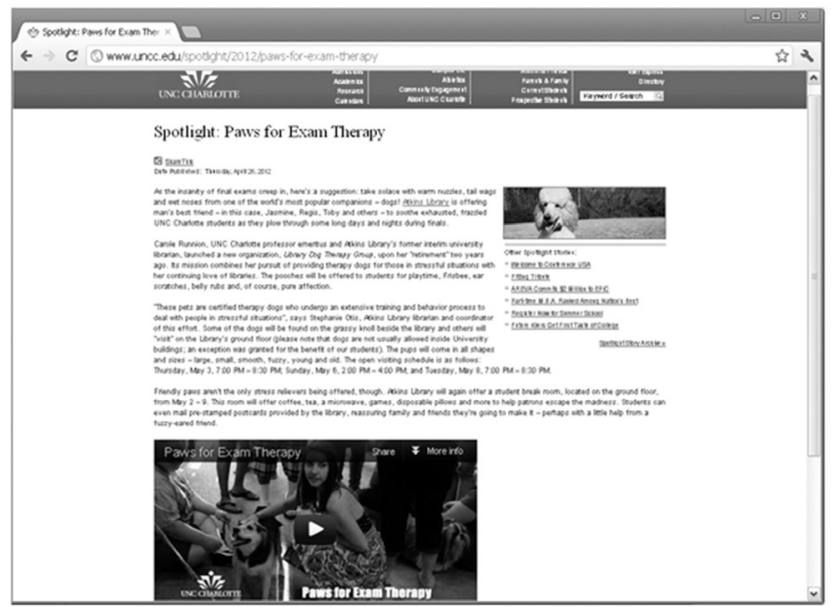

An article on the pet therapy session was displayed on the UNCC library's Web site. View this article online for detailed images.

taking a break. We also handed out fliers that employed the slippery slope advertizing method to add some humor. It appeared to be success- 
ful since students were laughing and showing them to their friends.

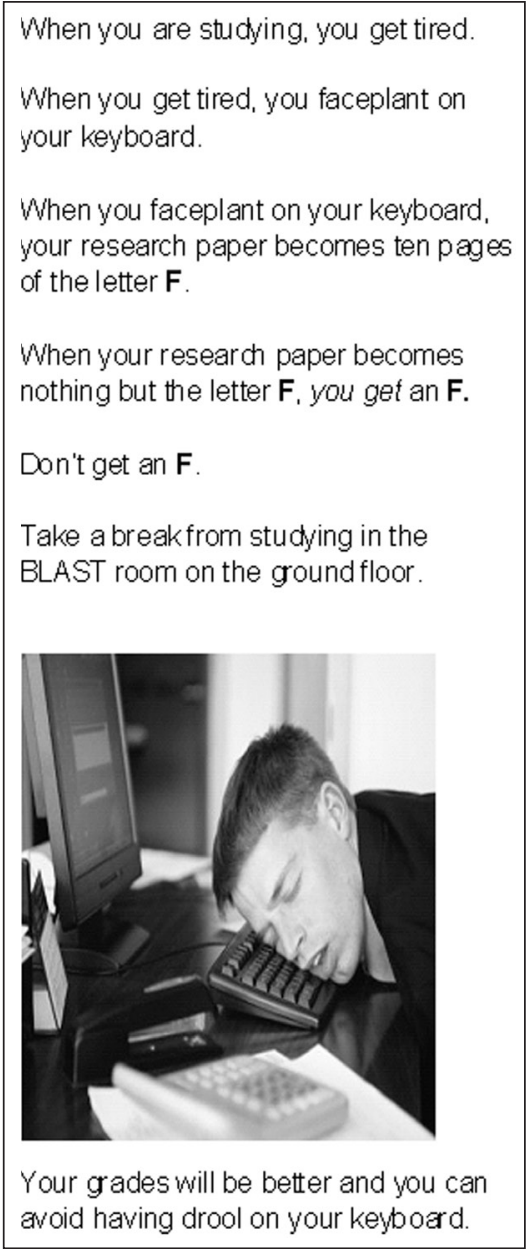

BLAST promotion.

\section{Lessons learned}

We were thrilled with the vast popularity of our finals BLAST activities. It was so popular, we were unable to keep up with restocking drinks and supplies using our four-hour schedule. Next semester, we're going to move to a two- or three-hour schedule. We were also surprised at how quickly the coffee and cocoa disappeared and hope to double the amount purchased in the future, if the budget allows.

For simplicity's sake, we only ordered pepperoni pizzas, thinking people who didn't like pepperoni could just remove them. We didn't take into account that some cultures do not eat pork products or food that has been touched by pork. In the future, we'll order plain cheese pizzas.

While we expected the materials to be used up or go missing (and some did), we controlled this by bringing out items in batches. We were pleasantly surprised by the artwork and messages students left for us, expressing their appreciation. We will provide space for them to post their art work in the future.

We plan to ask more dentist offices to donate toothbrushes and toothpaste because what we had went so quickly. The students were delighted when they realized they could keep the pillows. One student posted on Facebook, " [t]he UNC Charlotte Atkins Library has disposable pillows? We have such a hip, cool library!"

We need a bigger space for the pet therapy program as well. Although we were prepared for accidents, we didn't expect

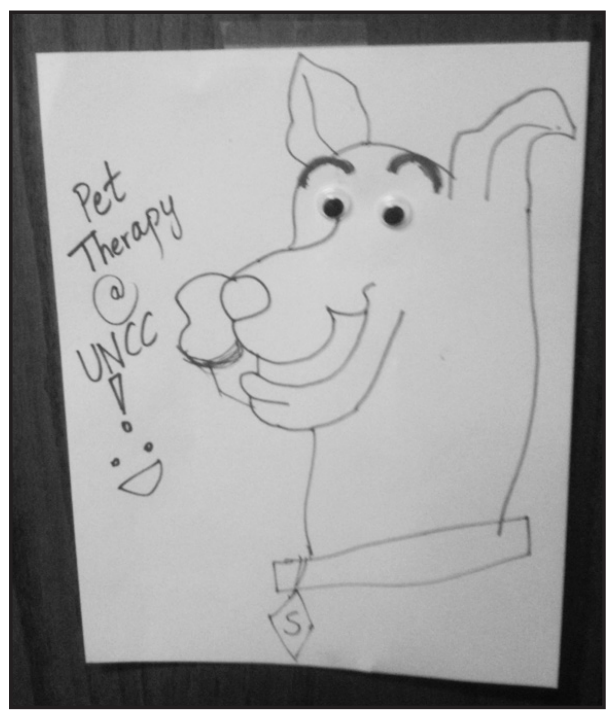

Art work left by one of students.

one of the dogs to vomit. On the three days we had arranged for them to come, it was either too hot or rainy to take them outside. Other libraries have taken dogs through the library rather than having the students come to them, and this may be the model we have to adopt.

(continues on page 546) 


\section{Lessons learned}

Want to try this at home? Here are some tips. When an urn is marked for 100 cups, it means 6-ounce tea cups. If you give away free refillable, library-approved 16-ounce mugs (as we did on our very first night), you will run out of coffee very quickly. Know that powdered cocoa mix can and will make a mess of your linens, and large quantities of piping-hot coffee grounds are hard to clean up. You can't have enough cookies and hot water. Urns may not fit under your faucet. Our first night we filled a punch bowl with water and asked a tall student to pour it in. We now own two one-gallon pitchers and they are filled and waiting to be poured into the next empty urn.

Ask your maintenance department for advice on where to plug things in so you don't blow a fuse. Also, check that any surge protectors you plan to use actually work. Always check that the spigot on the empty urn is closed before pouring in new water. Cloth kitchen towels are more useful than paper. Although our student workers help replenish supplies, we refrain from asking them to handle hot pots and urns.

\section{Assessment}

Spring 2012 marked our fourth Finals Coffee Break. It's difficult to find a metric to use to mark how much "business" we do, since we don't have time to count the number of students going through the line because we're so busy keeping the coffee bar stocked. We settled on counting the number of cups used. While this is an imperfect measure, at least it gives us a benchmark to compare from semester to semester. It's difficult to say whether we're moving more coffee because our building head counts are up, or if our head-counts are up because we're giving away refreshments. What's undoubted though is that we've seen an increase in the popularity of the event over these last four semesters. In the end, the success of the Finals Coffee Break is best measured by the grateful and happy expressions on the faces of our students. $\boldsymbol{n}$
("BLASTing the zombies," cont. from page 543)

Overall, the pet therapy was an incredibly successful activity and was a key angle in promoting all of our finals break room offerings. One student tweeted, "[t]here are dogs in the library right now. Atkins, are you trying to make me fail my comm theory exam?"

One other consideration is the university's policy on "non-service dogs" in a building. We ended up scrambling the day before their arrival to get express permission from the chancellor for the dogs to enter the building.

Although we asked students to post their comments about the BLAST room on our Facebook page or to tweet about it, they seemed to have preferred writing their comments on a white board. Perhaps it is better to catch them in the moment, before their minds stray back to more pressing issues. We plan to place more white boards near the entrance to the room as well as inside it. The comments they wrote were very positive ("this break room is amazing!") as were the comments they made to the staff who restocked and tidied the room.

\section{Conclusion}

Atkins Library has all types of spaces (i.e., quiet zones, group study rooms, collaborative work tables) to accommodate the different ways today's students study. We have a large commuting population that occupies the library between classes and is accustomed to the services we provide. We also have students who never use the library until exams are upon them. Trying to reach all of them can be like attempting to nail JELL-O to a tree-some of them slip away from us despite our best efforts. Friends, family, instructors, and student organizations are vying for the attention of the average student-getting their attention is the first step. Once you have it, the message must be clear: the library is genuinely invested in student success, and offers the personnel, spaces, technology, and services to achieve it. . . . and we definitely don't want them to eat our brains.

(continues on page 569) 
college librarian at Wheaton College in Massachusetts for 17 years before joining Bow-

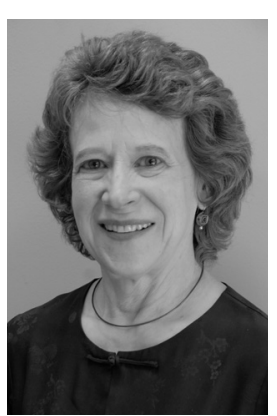

Sherrie Bergman doin. In recognition of her dedication to the college, the Bowdoin College Alumni Council presented Bergman with the 2012 Alumni Service Award for Faculty and Staff. Under Bergman's leadership, Bowdoin's HawthorneLongfellow Library underwent a $\$ 6.4$ million renovation (completed in 2005); collections grew to more than 1 million volumes; the George J. Mitchell Department of Special Collections and Archives, and the Bowdoin Digital Commons were established; and the scope of the library's offerings was expanded through shared library catalogs with Colby and Bates colleges, and the Maine InfoNet and NExpress consortia. Active professionally, Bergman's ALA involvement included service as chairperson of ACRL's College Libraries Section; president of ACRL-New England; ALA Councilor; cofounder of the LLAMA Women Administrators Discussion Group; membership on the Committee on the Status of Women in Librarianship; planning committees for several ACRL conferences; and active participation in the College Library Directors Mentoring Program and the Dr. E. J. Josey Spectrum Scholar Mentor Program.

Cathy Miesse, assistant dean for technical services and outreach, has retired after 27 years of service to the Loyola UniversityChicago Libraries. Miesse went to Loyola from Governors State University in July 1985, where she had been reference coordinator. At Loyola she was head of circulation and head of access services before assuming the position of assistant dean in 2006. Miesse is very active in ALA, especially with LLAMA, where she has held prominent positions on several committees. At Loyola she was responsible for the Friends of the Libraries Speaker Series, a mentoring program for new library faculty and staff, and the libraries' annual celebration of faculty scholarship.

Joe L. Storey, associate director and head of Collections Support Services at the St. Mary's College of Maryland Library, has retired after 33 years of service. $n$

\section{("Digital Humanities" cont. from page 539)}

of Maryland-College Park. Access: http://dhsi. org/ and http://mith.umd.edu/dhwi/.

- THATCamp. The Humanities and Technology Camps, described as "unconferences" with no formal agenda or presentations, have exploded across the country and worldwide in the last couple of years. All participants contribute, in a collegial setting, to creating tools, problem-solving, discussing issues, etc.
Camps are usually small, with an average of 75 participants. Access: http://thatcamp.org/.

\section{Notes}

1. For further resources, see our research guide "Digital Humanities" at http://guides. lib.cua.edu/digitalhumanities.

2. Visit http://codeyear.com for more information about the Code Year Web site. $\boldsymbol{n}$

("BLASTing the zombies," cont. from page 546)

\section{Notes}

1. Special thanks to the BLAST Committee: Marc Bess, Edna Dash, Betty Ladner, Donna Lanclos, Stephanie Otis, Beth Scarborough, and Shoko Tokoro.

2. The Paws for Exam Therapy video is located at http://youtu.be/XOPoNF7ZMnc $\boldsymbol{n}$ 